\title{
Antioxidant Functionality in Plants and Plant Sourced Biomaterials
}

\author{
Nene $\mathrm{AG}^{1 *}$, Xuefeng $\mathrm{Y}^{1}$, Hongrong $\mathrm{L}^{1}$ and \\ Ramakrishna $\mathbf{S}^{2}$ \\ ${ }^{1}$ Shenzhen Institutes of Advanced Technology, Chinese \\ Academy of Sciences, China \\ ${ }^{2}$ National University of Singapore, Singapore \\ *Corresponding author: Nene AG, Shenzhen \\ Institutes of Advanced Technology, Chinese Academy of \\ Sciences, Shenzhen, 518055, China; Email: neneajinkya@ \\ gmail.com
}

Received: May 22, 2020; Accepted: J une 15, 2020;

Published: J une 22, 2020

\begin{abstract}
Antioxidants play vital role in neutralizing / removing harmful oxidants produced in human body as well as they are utilized in food technology for applications such as food packaging by introduction into bio films. Plant (land and marine) based biomaterials such as cellulose, starch etc. has tremendous potential in food packaging and other food science applications to enhance food shelf life, protection from external factors and keeping quality intact. Addition of antioxidants; in bio films based on these biomaterials are advantageous as these biomaterials are natural, non toxic and easy availability. Plants are also a source of natural antioxidants and are utilized in dietary, medicinal applications in traditional medicine techniques such as Traditional Chinese medicine and Ayurveda. Present review summarizes recent developments and understanding of 'antioxidant functionality of plant based biomaterials in food science'. An illustration on health and medicinal benefits of natural antioxidants included in Traditional Chinese Medicine (TCM) and Ayurvedic is incorporated.
\end{abstract}

Keywords: Antioxidants; Classification of Antioxidants; Mechanism; ROS; RNS; Biomaterials; Traditional Chinese Medicine; Ayurveda

\section{Introduction}

Plants containing antioxidant compounds and plant based biomaterials are abundantly available and highly potential for applications in Food science. They can play key roles not only in food packaging, food preservation but also in controlling diseases, diet and nutrition. With respect to food science PFA i.e. Prevention of Food Adulteration a instead a for ward act says that antioxidants are substances which when added to food retards or prevents oxidative deterioration food and does not include sugars, cereal oils, flours, herbs and spices [1]. Market value of food product decreases due to oxidation as it affects on organoleptic properties and destroying essential nutrient properties. Antioxidants help in slowing down oxidation in food as well as human systems. During decades antioxidants are being used in foods as a main strategy to prevent food spoilage [2]. Another approach to limit oxidation in food is active packaging. In this aspect an innovative alternative is the use of active antioxidant packaging systems [3]. Antioxidant agents added to films and edible coatings can modify their structure, functionality to improve chemical stability and protect ozidant sensitive food [4, 5]. Recently, use of active food packaging has been shown prominent effects in controlling food deterioration and in enhancing shelf life at the same time keeping quality of food product intact [2]. Packaging not only play a key role in food supply chain but also acts as barrier to control food from external influences such as oxygen, light, moisture and both from chemical and microbiological contamination $[3,6]$.

A material with a natural or synthetic origin in contact with a bio system without affecting it can be considered as a Biomaterial. A wide range of biomaterials are in use for diverse applications in medicines and controlled drug delivery, tissue engineering, regenerative medicine, stem cells, biomedical engineering, bioengineering, biotechnology, and health supplements [7-10]. A variety of polymers have been used as biomaterials which are synthesized by plant [10]. For example - Cellulose is one the most abundant natural polymer existing on earth which is also a major constituent in plant cell wall. Cellulose is a source of fibers in fabrics and number of plastics have been made by replacing hydroxyl group present on glucose moiety of cellulose [11]. Various approaches have been developed and used to modify mechanical, structural and biochemical properties of biomaterials for their innovative applications [12].

Lack of antioxidants in food extinguishes ROS i.e. reactive oxygen species, clears the way for diseases (like cardiovascular diseases, cancers, neurodegenerative diseases and inflammatory diseases) as well as food spoilage [13, 14, 3-6]. Including natural antioxidants by means of natural plants that contains antioxidant compounds in diet can solve this problem. Natural antioxidants are helpful in biological functions as they can prevent diseases and also having dietary importance [15-17]. The natural plants or natural antioxidants therefore play an important role in nutritional as well as health benefits [18]. For thousands of years plants have been basis of Traditional Chinese Medicines and Ayurveda and continue to provide remedies with lesser or no side effects on health [19-21].

In this review antioxidant functionality of biomaterials deriving from land plants and marine algae is illustrated with respect to applications in food science. Introduction to antioxidants, free radicals, antioxidant mechanisms are explained in short. Plant based biomaterials are biodegradable, biocompatible and nontoxic and easily available. Some of these plants based biomaterials show antioxidant properties or may possess improved antioxidant functionalities with the addition of either antioxidants or extracts containing antioxidants. These modified biomaterials can be formulated into films, nanoparticles etc. for applications in food packaging. TCM (Traditional Chinese Medicines) and Ayurveda,
Austin J Nutr Metab - Volume 7 Issue 3 - 2020

Submit your Manuscript | www.austinpublishinggroup.com

Nene et al. (c) All rights are reserved 
including plants that are having antioxidant compounds, make them useful in food supplements and medicine.

\section{Antioxidants, free radicals and antioxidant mechanism}

Antioxidants-as the name indicates ('Anti' meaning against; and 'Oxidants' meaning oxidation causing) - are the molecules which deactivates/neutralizes the oxidation preventing free radical production. Antioxidants are not different class of molecules by themselves (say acids, bases, alcohols, aldehydes, ketones, etc.) but represent the property and ability possessed by them to chemically neutralize free radicals so that they become harmless - particularly in living organisms and human beings [22,23]. Oxidation is a chemical reaction in which one electron (unpaired electron) is transferred from one molecule to an oxidizing agent [24]. Oxidizing agent causes the oxidation of the neutral molecule. Thus, oxidizing agent gains electron while the molecule loses it (electron "leakage"). Converse is true for reduction reaction. A chemical reaction that involves both oxidation and reduction reactions is called as a redox reaction. Oxidation reactions are known to produce free radicals - containing unpaired electron in their outermost shells - (i.e. outermost shell is not completely filled by electrons) - having high chemical reactivity. Such radicals initiate chain reactions in an uncontrolled manner which is harmful and undesired by human/organism body. Antioxidants react with these free radicals thereby terminating the chain reaction and inhibiting other undesired oxidation reactions via oxidizing themselves $[25,26]$.

Antioxidants are classified according to whether they have been obtained from a natural source (Natural Antioxidants) or have been synthesized (Synthetic antioxidants) (Figure 1).

Free radicals reactions can produce deteriorating and adverse effects in body and number of degenerative diseases can occur such as diabetes, atherosclerosis, inflammatory diseases (rheumatoid arthritis, inflammatory bowel diseases and pancreatitis), Ischemia/ Reperfusion (l/R) injury, cancer, neurological diseases, hyper tension etc. $[27,28]$.

\section{Causes for free radicals generation}

- Radiations: UV radiations, X-rays, gamma rays and microwave.

- Initiation by inflammation.

- Pollutants $\left(\mathrm{O}_{2}\right.$ free radicals).

- Electron transport reactions catalyzed in mitochondria.

- Platelets, macrophages, smooth muscles metabolism generates reactive oxygen species.

- $\quad$ Organic matter burning.

Free radicals are mainly described as ROS (reactive oxygen species) and RNS (reactive nitrogen species) also some other nonreactive species. Apart from harmful effects free radicals have useful properties as released oxygen species are important in growth processes and White blood cells release can release free radicals as an immune response against pathogens $[29,30]$.

Figure 2 shows different types of ROS and RNS. Oxidation rates in a biological system slowed down by antioxidants by combining

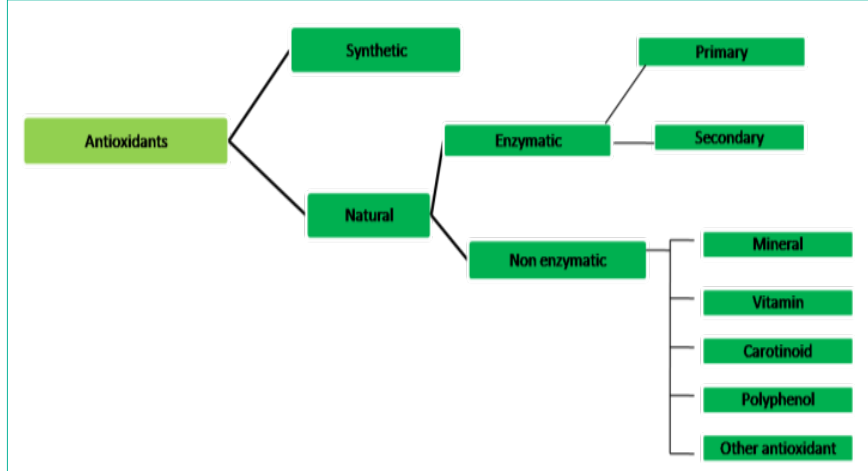

Figure 1: Synthetic and natural antioxidants: Types of antioxidants.

\begin{tabular}{|c|c|}
\hline & \\
\hline $\begin{array}{l}\text { - Ozone }\left(\mathrm{O}_{3}\right) \\
\text { - Oxygen singlet }\left(\mathrm{O}_{2}\right) \\
\text { - Hydroxyl peroxide } \\
\left.\text { ( } \mathrm{H}_{2} \mathrm{O}_{2}\right) \\
\text { - } \mathrm{Hydroxyl} \text { radical } \\
\text { (OH) } \\
\text { - Peroxide (ROOH) } \\
\text { - Hypochlorous acid } \\
\text { (HOCl) } \\
\text { - Hydroperoxyl } \\
\text { radical }\left(\mathrm{HO}_{2}\right)\end{array}$ & 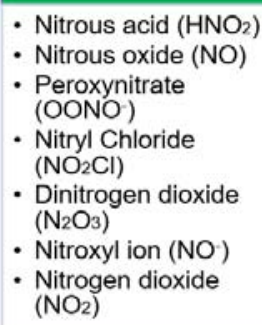 \\
\hline
\end{tabular}

Figure 2: Types of ROS (Reactive Oxygen Species) and RNS (Reactive Nitrogen species).

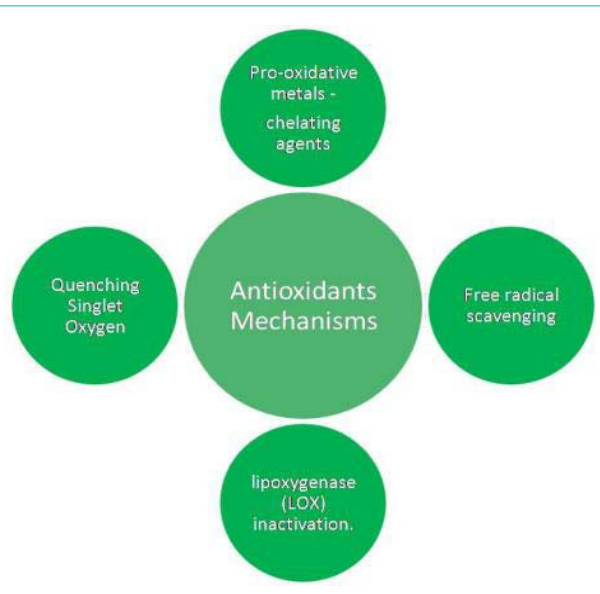

Figure 3: Mechanisms of antioxidants

chelating pro-oxidative metals, quenching singlet oxygen, scavenging free radicals and by inactivating Lipoxygenase (LOX) [31]. Figure 3 shows mechanisms related to antioxidants. Antioxidants have ability to slow down the oxidation rates or oxidising chain reactions are inhibited in different ways such as: free radical scavenging, by chelating agents (pro-oxidative metals), by quenching singlet oxygen and by lipoxygenase inactivation. Bendary et al. proposed two mechanisms of action for antioxidants which includes bond dissociation energy and one-electron transfer mechanisms [32].

Below (Figure 4) are some reaction schemes of antioxidants which represent basic action of antioxidants. Antioxidants can neutralize 


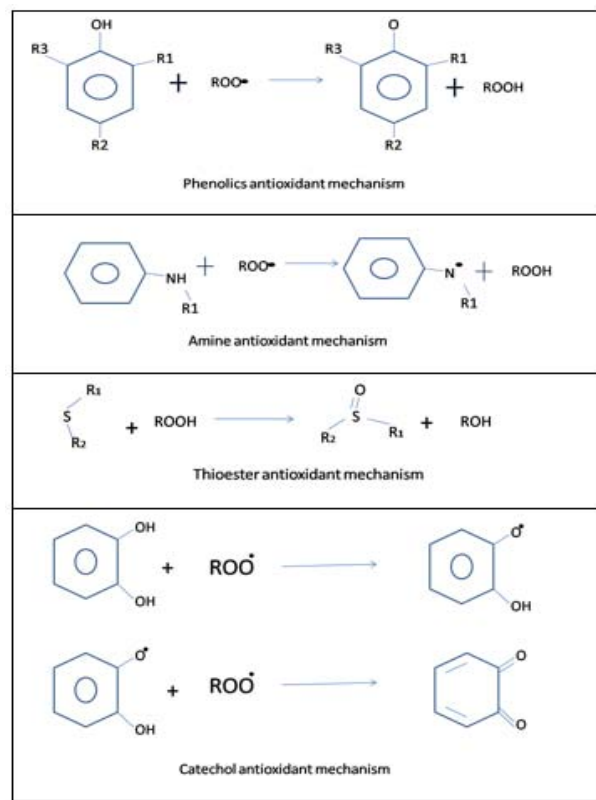

Figure 4: Basic antioxidant reactions.

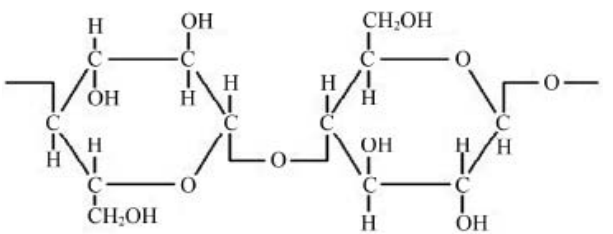

Figure 5: Structure of Cellulose [40].

and terminate free radicals. An electron is donated to free radical hence it is neutralized before any damage to cell components occurs. Once electron is donated, free radical becomes paired and hence no more hazardous to cells. In case of phenolics antioxidant mechanism, primary antioxidants can react with peroxy free radicals (ROO•) to prevent this cycle. Amine antioxidant is another primary antioxidant. Amines have better reactivity with oxygen-centered free radicals than phenols. Peroxide reacts with thioester and by which nonreactive, free radicals are produced. Following are some schematic representations of antioxidant mechanisms [32-35].

\section{Antioxidant functionality of biomaterials with Plant origin (land and marine)}

Cellulose: Cellulose is a natural biopolymer which is versatile and abundant in nature. Figure 5 shows structure of cellulose. It possess desirable biological and mechanical properties, porocity, water absorbancy, unique surface chemistry, excellent biological activity is [36-38]. Structure of cellulose consists of a linear homopolymer of b-d-glucopyranose units linked together by (1/4)-glycosidic bonds. Due to hydroxyl groups present largely on the surface, it has advantage to incorporate with biomaterials for magnified antioxidant properties [39].

However cellulose has very low antioxidant property and it limits its direct use as antioxidant or bio films. But incorporation of synthetic and chemical antioxidants in cellulose based films is an alternative to enable its use in food technology [37]. Production of cellulose packaging films with strong antioxidant capability can be a good choice in global health market as cellulose is a cheap and abundant source in nature $[37,41]$.

Cellulose biopolymers exist as Carboxymethylcellulose (CMC), Hydroxyethylcellulose (HEC), Hydroxypropylmethylcellulose (HPMC) and Methylcellulose (MC). Cellulose pure dispersions and films show very low antioxidant activity however when mixed with pomegranate seed extract results in potent antioxidant activity; it also decreased swelling and tensile strength, increased elongation at break. This combination could prove to be potent food packaging material [37]. Antioxidant property (free radical scavenging) can be improved by increasing the essential oil (such as Rosemery and Aloe Vera oil) content in cellulose based membranes [41]. Also cellulose based membranes incorporated by essential oils can inhibit lipid oxidation, growth of $\mathrm{pH}$ and chemical spoilage and this provides a platform for potential food packaging films production $[39,41]$.

Velasquez et al. reported a biodegradable antioxidant system for food packaging applications with enhanced physical-mechanical properties. Cellulose along with quercetin and Poly(Lactic Acid) (PLA) were utilized to form a bilayer structure and their characterization was done in this work. Bilayer with $30 \mu \mathrm{m}$ thickness obtained with good permeability [42]. Criado et al. reported antioxidant functionalized cellulose nanocrystals after intercalation treatment with a redox pair hydrogen peroxide $\left(\mathrm{H}_{2} \mathrm{O}_{2}\right)$ [43]. Davoodbasha et al. reported nanoceria coated with cellulose which showed strong hydroxyl, DPPH, superoxide and $\mathrm{H}_{2} \mathrm{O}_{2}$ radicals scavenging activity in a $\mathrm{pH}$-depended manner. This material provides potential antioxidant material for targeted therapy so as to inhibit the intracellular ROS and oxidative stress [44].

Starch: Starch a storage polysaccharide derived from tuber and cereals plants such as potato also abundant in nature. A starch molecule is typically made up of $30 \%$ amylase and $70 \%$ amylopectin, this overall content varies with source of extraction.

Chen et al. reported functionalized starch derivatives using "click" reaction and $\mathrm{N}$-alkylation in order to achieve chemical modification to improve antioxidant property. Chemical modifications in starch are feasible due to Anhydro Glucose Unit (AGU) providing three active hydroxyl groups, including one primary and two secondary hydroxyl groups. Chemically modified starch derivatives show enhanced antioxidant properties when compared to pure starch and they are reactive against superoxide radicals. These functionalized starch derivatives are highly potential antioxidant material and can be applied in food science applications as well as biomedicines [45]. Azmi et al. reported polyaniline loaded starch films produced by solution casting method, which showed that incorporation of polyaniline significantly affects antioxidant properties of starch film with an increased free radical scavenging capacity (a measure of antioxidant activity). Free radical scavenging capacity of this material is directly proportional to polyaniline loading irrespective of its size. Starch/polyaniline films could prevent deterioration in food constituents [46]. Navarro et al. fabricated starch-chitosan films further modified by adding aqueous extracts of cranberry, blueberry, beetroot, pomegranate, oregano, pitaya and resveratrol. This addition not only makes it more potential for food packaging applications 


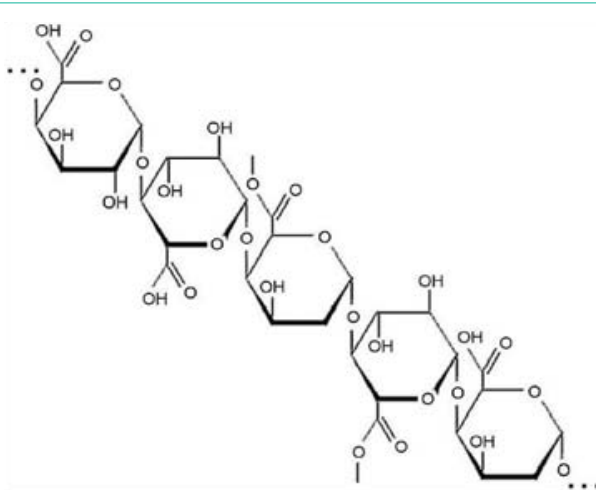

Figure 6: Structure of Pectin [49].

but also natural antioxidants such as anthocyanins (from cranberry; blueberry and pomegranate); betalains (from beetroot and pitaya); resveratrol (from grape); and thymol and carvacrol (from oregano) were added to the films. This shows a positive impact and makes suitable for food packaging applications [47].

Pectin: Pectins are complex carbohydrate molecules and can be used as gelling agents in food applications [48]. Pectin has high molecular weight and hydrophilicity; a natural constituent of plant call wall is ideal material (Figure 6 shows structure of pectin) for hydrogel formation and subsequently 3D bio-printing. Pectins are complex carbohydrate molecules that are used in numerous food applications as a gelling agent $[48,49]$.

Smirnov et al. isolated pectin fractions or pectin polysaccharides from vegetables. They show antioxidant activity due to against the hydroxyl and 1, 1-diphenyl-2-picrylhydrazyl radicals due to presence of protein $(2-9 \%)$ and phenolics $(0.5-0.7 \%)$ as contaminants. The antioxidant activity of pectin gets enhanced due to the presence of non-pectin contaminants. This research represents possible new approaches in food analysis and supports dietary guidelines using beneficial pectic polysaccharides [50]. In case of pectin fraction isolated from onion shows inhibition to production of superoxide radical by means of inhibiting XO i.e. Xanthine Oxidase [50]. Being a primary plant metabolite, pectins in plant are able to react on ecophysiological conditions.

Despite a lot of research has been carried out to extract pectin with high antioxidant properties, lacks study on its applications in food technology. Significant differences in structure are not reported although yield affected by extraction method and conditions as compared to commercial pectin.

Edible and biodegradable pectin films with antioxidant properties can be used to extend shelf life of perishable food items [51, 52]. Pectin films incorporated with food extracts are having higher antioxidant capabilities and they are cheap, renewable and sustainable. Acerola (fruit similar to cherry) incorporated pectin films possess highest antioxidant capabilities so as to use in many food applications [53]. Pectin based films incorporated with plant extracts are potential to be used in extending food shelf life. Pectin film fabricated after pectin extracted from tejocote (species of hawthorn) shows higher antioxidant activity than commercial pectin. In this work pectin was extracted by an acid hydrolysis process with citric acid [54]. Zaidel et

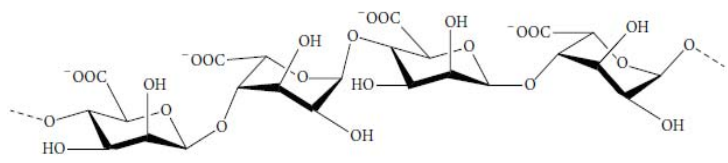

Figure 7: Structure of Alginate [56].

al. reported that low methoxyl pectin extracted from dragon fruit has high antioxidant activity [48].

Yang et al. did a comparative study between PHA i.e. pectin hydroxamic acids and among various commercial pectins with different Degrees of Estarification (DE). Result expressed that pectin hydroxamic acids shows antioxidant properties also higher DE pectin derivatives show higher antioxidant properties. Biological activities of pectin hydroxamic acids need to be investigated not only for food industry of jams and jellies but also for other aspects [55].

Alginate: It is sourced from brown algae such as Laminaria hyperborean, Laminaria digitate, Laminaria japonica, Ascophyllum nodosum, and Macrocystis pyrifera and its one of the common material used in 3D bioprinting. Figure 7 shows structure of alginate. The copolymer structure is based on polysaccharides (b-D-Mannuronicacid (M) and a-L-Gluloronic acid (G) with blocks of $\mathrm{G}$ and $\mathrm{M}$ residues and alternating $\mathrm{M}, \mathrm{G}$ residues [9]. In brown seaweeds exists as a cationic salts mixture in cell wall and matrix. Sodium alginate extracted from Cystoseira barbata (Tunisian seaweed) has interesting antioxidant nature also can be used as a food additive [57]. Alginate/gelatin hydrogels are potential carrier for natural antioxidants and suitable for biomedical applications as hydrogel based on natural polymers are advantageous over synthetic once. Alginate/gelatin hydrogels has potential application to be used in controlled release of bioactive agents in a matrix type system [58]. Kokilam et al. reports that alginate yielding seaweeds (Sargassum wightii Greville, Padina tetrastromatica Hauck, Chnoospora minima, and Hormophysa triquetra) can be used as a source of natural antioxidants and their crude extracts bares good antioxidant properties. This gives their potential applications as natural antioxidants in food and pharmaceutical products [59].

Hadiyanto et al. encapsulated alginate with phycocyanin (a blue light pigment in cyanobacteria, Rhodophyta and Crytophyta) and reported that encapsulated phycocyanin-alginate possess higher antioxidant activity and has more stability at high temperature than phycocyanin alone (without encapsulation). Encapsulation at $2.5 \%$ of phycocyanin showed higher antioxidant activity [60]. Also edible films by incorporating lipids in alginate possess strong antioxidant properties. Another advantage of adding lipid to alginate films is that it enhances water vapour permeability. Alginate lipid edible film added with natural antimicrobial agents is of great use in food science [61].

Fucodian: A polysaccharide, ROS scavenger, consists of L-fructose and sulphate group has attracted attention from food and pharmaceutical industries for its antioxidant and therapeutic properties. Structure of fucodian is represented in Figure 8. Fucodian extracted from Laminaria japonica has a potential to treat diseases by free radical damage capability because of antioxidant nature [9]. Parallely it is reported that extracted from U. pinnatifida possess strong antioxidant properties which can reduce amyloid 


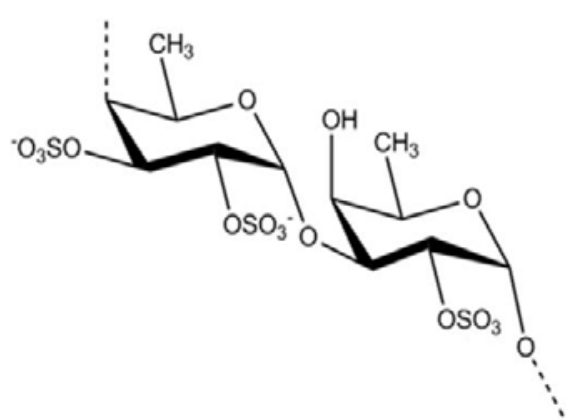

Figure 8: Structure of Fucodian [62].

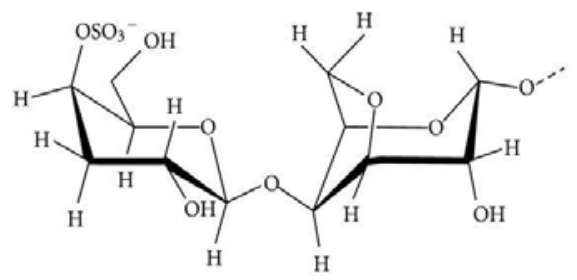

Figure 9: Structure of Carrageenans [69]

accumulation and ROS. In skin care products fucodian is used as neuro health foods due to its natural antioxidant properties. Factors affecting antioxidant property in fucodian are concentration, $\mathrm{Mw}$, the degree of sulphation, substitution groups and their positions, type of sugar, glycosidation branching, substituent's. Chemical modifications in fucodian can enhance its antioxidant properties. Fucodian has a potential applications in neutraceuticals, ROS-related diseases to promote health [62-64].

Wang et al. reported that antioxidant fucodian can regulate the expression and activity of Matrixmetalloproteinase-9 (MMP9) in human fibrosarcoma cells. Other positive benefits of fucodian such as: antitumor, antiviral, immunoregulator, anti-inflammatory, anticoagulant are mentioned. [64]. Kordjazi et al. extracted fucodian from Sargassum ilicifolium and Sargassum angustifolium and it showed strong antioxidant properties with DPPH, superoxidehydroxyl radical scavenging, chelating ability and reducing power. Results suggest that fucodian extracted from S. ilicifolium and S. angustifolium had more than $80 \%$ of scavenging effect on hydroxyl radicals therefore proven as natural and safe antioxidant agents in nutraceuticals [65].

Fucodian exhibits comparable antioxidant property with that of synthetic antioxidants such as Butylated Hydroxyanisole (BHA) and Butylatedhydroxytoluene (BHT). Extracted fucodian from Undaria pinnatifida grown in New Zealand possess nearly equal antioxidant property however low molecular fucodian shows higher antioxidant nature when compared with Butylated Hydroxyanisole (BHA). Focodian isolated from Undaria pinnatifida has potential applications in food industry as a functional ingrediant [66]. When compared with ascorbic acid and pure fucodian standards fucodian extracted from sea mustard sporophylls (Tongyeong and Gijang City) expressed low scavenging activity on DPPH, superoxide, and hydroxyl radicals. This in concluded because of impurities present in the crude fucoidan extracted supported by protein present more than
$0.1 \%$. The studies show possible utilization of sea mustard sporophylls which are a byproduct in sea weed industry; as a source of fucodian for various applications in food industry [67].

Bushra et al. reported that oxidative status in kidney tissue improvement and histological protectionagainst Cyclosporine A -induced kidney injury resulted due to fucodian. Fucodian administration with Cyclosporine A (an immune suppressive drug) enhanced renal function. Results highlights renoprotective effects of fucodian by means of controlling oxidative stress conditions and improves kidney injuries [68].

Carrageenan: Carrageenans (structure denoted in Figure 9) are complex family of water soluble, linear, sulfated galactans of red seaweeds [70]. Carrageenan is a relatively under researched polygalacton derived from the Rhodophyceae members of red algae seaweeds. The material is composed of alternating long chains of a-1, 3 D-galactose, and b-1, 4 3, 6-anhydro-galactose with ester sulfates which emulate the structure of mammalian glycosaminoglycans [9]. Comparative study among different molecular weights of k-carrageenan, highest antioxidant activity is observed at low molecular weight [71].

The results indicated that carrageenans possess antioxidant capacity in vitro, and this action notably depends on the structure of the polysaccharide itself than the reducing capacity of the polysaccharides. Antioxidant actions (based on hydrogen atom transfer) of carrageenans depends on polysaccharide concentration, medium $\mathrm{pH}$ value and the polysaccharide fine structural characteristics [70].

The chemical modification of carrageenan oligosaccharides could enhance their antioxidant activity and different derivatives of carrageenan oligosaccharides exhibited higher antioxidant activity than the carrageenan oligosaccharides in certain antioxidant systems in vitro [71]. Carrageenan-SEO (SEO- Satureja hortensis) composite films obtained by emulsification as a natural antibacterial agent can potentially be used in packaging a wide range of food products, particularly those that are highly oxidative and microbial sensitive [72].

A multilayer coating based on carrageenan and quercetin loaded lecithin/chitosan Nanoparticles $(\mathrm{Np})$ by the layer-by-layer technique is biocompatible with good antioxidant property so as to scavenge free radicals to form biocompatible thin films in food science applications [73]. Table 1 represents antioxidant potentials in biomaterials derived from marine and terrestrial plants.

\section{TCM and Ayurvedic plants as natural antioxidant}

Traditional Chinese Medicines (TCM): Since thousands of years TCMs are being used to treat diseases in China. They are also known as inflammatory modulators and clinically safe. This is because of their low toxicity and therapeutic effects. Modern Biological assays and phytochemical tests reveal that TCM possess high antioxidant properties also due to phenolic and flavonoid components. Table 2 explains different uses of TCM.

Ayurvedic: Ayurveda (Indian Traditional Medicine Science) is a science dealing with physical and mental health. Several plants, animal, and natural sources of materials are used in Ayurvedic 
Table 1: Antioxidant functionalities in biomaterials: Marine and terrestrial plants.

\begin{tabular}{|c|c|c|c|c|}
\hline No. & Antioxidant & Source & Usefulness/application & Reference \\
\hline 1 & Cellulose & Plant-derived storage polysaccharide & $\begin{array}{l}\text { Low antioxidant property, bio-films of cellulose } \\
\text { incorporated with other antioxidants in food } \\
\text { technology }\end{array}$ & {$[37,41,9]$} \\
\hline 2 & Starch & Plant-derived storage polysaccharide & $\begin{array}{l}\text { biomedicine, pharmaceutical, food, textile, } \\
\text { environmental protection }\end{array}$ & {$[45,46,9]$} \\
\hline 4 & Alginate & $\begin{array}{l}\text { Brown algae, commonly Laminaria hyperborean, Laminaria digitate, } \\
\text { Laminaria japonica, Ascophyllum nodosum, and Macrocystis Pyrifera etc. }\end{array}$ & Natural additive in food applications, antioxidant & [9] \\
\hline 12 & Pectin & $\begin{array}{l}\text { Primary cell wall and intracellular substance of higher plants, vegetables } \\
\text { (Brassicaoleracea convar, Daucuscarota subsp. Sativus, Allium cepa var. } \\
\text { cepa (yellow onion), Capsicumannum var. annum (red bell pepper) }\end{array}$ & $\begin{array}{l}\text { Possess ROS scavenging Activity, extend shelf } \\
\text { life of food }\end{array}$ & [50-52] \\
\hline 13 & Fucoidan & Brown seaweeds (Sargassum ilicifolium, Sargassum angustifolium). & Antioxidant and Anti-tumor properties. & {$[63,65]$} \\
\hline 14 & Red algae & Carrageenan & Strong antioxidants & {$[70,71]$} \\
\hline
\end{tabular}

Table 2: TCM: sources and uses.

\begin{tabular}{|c|c|c|}
\hline TCM & Use & Reference \\
\hline Shanzha (fruit of Crataegus pinnatifida) & To treat cardiovascular diseases, prevents thrombosis, promotes digestion & {$[74,75]$} \\
\hline Danshen (the root of SalviaMiltiorrhiza) & To treat cardiovascular diseases, promotes blood circulation, tissue regeneration & [74] \\
\hline Salvia miltiorrhiza & Scavenge free radicals, treatment of angina pectoris, chest tightness & [76] \\
\hline Rhizoma ligustici & Anginal pain, stroke, abdominal pain, irregular menstruation, dysmenorrhea and amenorrhea & {$[76,77]$} \\
\hline Camellia sinensis (Chinese green tea) & Antioxidant with positive health effects & {$[76,78,79]$} \\
\hline Terminalia catappa L. & Scavenging free radical, total antioxidant activity of $28800 \pm 9600(\mu \mathrm{g} / \mathrm{g}$ dry weight) & [80] \\
\hline Chrvsanthemum & Highest phenolic content, radical scavenging activity & [81] \\
\hline Artemisiavulgaris & Potential effective source of antioxidants, radical scavenging & {$[82,83]$} \\
\hline Sanguisorba officinalis & Potential effective source of antioxidants, treatment of hemostasis and inflammation, & {$[82,84]$} \\
\hline Paeonia suffruticosa & $\begin{array}{l}\text { Inhibits antibiotic resistant pathogens, high free radical scavenging capacity, ion-chelating ability, anti-photo- } \\
\text { aging }\end{array}$ & {$[82,85,86]$} \\
\hline Cinnamomum cassia & Inhibits antibiotic resistant pathogens, radical scavenging abilities & {$[82,87]$} \\
\hline Lypocodium serratum (Jin Bu Huan), & Mild sedation & [81] \\
\hline Ephedra sp. (Ma-Huang), & Weight loss & [81] \\
\hline Angelica dahurica & Anti-tumor, antibacterial, analgesic & [88] \\
\hline
\end{tabular}

Table 3: Ayurvedic: sources and uses.

\begin{tabular}{|l|l|l|}
\hline \multicolumn{1}{|c|}{ Ayurvedic herb } & \multicolumn{1}{c|}{ Use } \\
\hline Desmodium gangeticum & Active scavenging abilities, febrifuge, digestive, anticatarrhal, antiemetic \\
\hline Glycyrrhiza glabra & Scavenging abilities, antioxidant, cytotoxic, and antimicrobial \\
\hline Picrorhiza kurroa & Reduceslipid peroxidation, antioxidant, antiinflammatory and immunomodulatory activities \\
\hline Psoralea corylifolia & Treatment of various skin diseases, laxative, aphrodisiac, anthelminitic, diuretic and diaphoretic in febrile conditions & [94,95] \\
\hline Emblica officinalis & Antiatherogenic, antitussive, immunemodulator \\
\hline Withania somnifera & Rejuvenating effect, promotes growth in children, anti-aging \\
\hline Glycerrhiza glabra & Therapeutic and antioxidant & [100,101] \\
\hline Mangifera indica & Protection against oxygen-derived species, protection from oxidative stress-related diseases \\
\hline Curcuma longa & Cytotoxicity, antioxidant and anti-inflammatory, anticancer \\
\hline Momordica charantia & Blood glucose level reliever, antioxidant, antimicrobial, antiviral, antihepatotoxic and antiulcerogenic activities \\
\hline
\end{tabular}

medicines. Ayurveda is an oldest medical system which is approved by WHO (World Health Organization) in 1974. An Ayurveda approach consists of both prevention and treatment of various diseases. Ayurvedic herbs possess various health benefits as well as strong antioxidant activity [89-92]. Table 3 explains sources and uses of Ayurvedic herbs.

\section{Concluding Remarks}

Present article briefly reviews antioxidants, plant (land and marine) based biomaterials, antioxidant functionalities of these biomaterials, applications in food science/technology and their recent developments. Significant work has already been done on antioxidants and their role in keeping the oxidative stress low and 
preventing various diseases and combining them with plant based biomaterials for applications such as food packaging, edible bio-films etc.. TCM and Ayurvedic methods reveals that our ancestors might be knowing indirectly about these compounds (i.e. antioxidants) although modern experimentation and characterization tools were not available. These methods include use of plant based natural antioxidant for medicinal, dietary/nutritional purpose in betterment of health aspects. This highlights the need for regular day-to-day intake of sufficient quantity of antioxidants. Developing processes for extraction of antioxidants from the natural sources, their long time preservation, and making them available at low cost is still a challenge to be tackled.

\section{References}

1. Singh RL, Sapna Sharma, Pankaj Singh. Antioxidants: Their Health Benefits and Plant Sources. Prakash, D., Sharma, G. editors. In: Phytochemicals of nutraceutical importance. CABI. 2014; 248-265.

2. Mbah CJ, Orabueze I, Okorie NH. Antioxidants Properties of Natural and Synthetic Chemical Compounds: Therapeutic Effects on Biological System. Acta Scientific Pharmaceutical Sciences. 2019; 3: 28-42.

3. Birben E, Sahiner UM, Sackesen C, Erzurum S, Kalayci O. Oxidative stress and antioxidant defense. The World Allergy Organization journal. 2012; 5: 9-19.

4. Salehi B, Martorell M, Arbiser JL, Sureda A, Martins N, Maurya PK, et al. Antioxidants: Positive or Negative Actors?, Biomolecules. 2018; 8: 124.

5. Alam MN, Bristi NJ, Rafiquzzaman M. Review on in vivo and in vitro methods evaluation of antioxidant activity. Saudi Pharmaceutical Journal. 2013; 21 143-152.

6. Yildirim S, Rocker B, Pettersen MK, Nilsen-Nygaard J, Ayhan Z, Rutkaite R et al. Active Packaging Applications for Food. Comprehensive Reviews in Food Science and Food Safety. 2018; 17: 165-199.

7. Varoni EM, Iriti M, Rimondini L. Plant Products for Innovative Biomaterials in Dentistry. Coatings. 2012; 2: 179-194.

8. Modulevsky DJ, Cuerrier CM, Pelling AE. Biocompatibility of Subcutaneously Implanted Plant-Derived Cellulose Biomaterials. PloS one. 2016; 11 e0157894.

9. Jovic TH, Kungwengwe G, Mills A, Whitaker IS. Plant-Derived Biomaterials: A Review of 3D Bioprinting and Biomedical Applications. Front Mech Eng. 2019; 5.

10. Moire L, Rezzonico E, Poirier Y. Synthesis of novel biomaterials in plants Journal of Plant Physiology. 2003; 160: 831-839.

11. Sannino A, Demitri C, Madaghiele M. Biodegradable Cellulose-based Hydrogels: Design and Applications. Materials. 2009; 2: 353-373.

12. Song R, Murphy M, Li C, Ting K, Soo C, Zheng Z. Current development of biodegradable polymeric materials for biomedical applications. Drug design, development and therapy. 2018; 12: 3117-3145.

13. Mishra K, Ojha $\mathrm{H}$, Chaudhury NK. Estimation of antiradical properties of antioxidants using DPPH assay: A critical review and results. Food Chemistry. 2012; 130: 1036-1043.

14. Hamid AA, Aiyelaagbe OO, Usman LA, Ameen OM. Lawal A. Antioxidants: its medicinal and pharmacological applications. Afr J Pure Appl Chem. 2010; 4: 142-151.

15. Sommerburg O, Keunen JE, Bird AC, van Kuijk FJ. Fruits and vegetables that are sources for lutein and zeaxanthin: the macular pigment in human eyes. The British journal of ophthalmology. 1998; 82: 907-910.

16. Kozłowska A, Szostak-Weggierek D. Flavonoids-Food Sources, Health Benefits, and Mechanisms Involved. In: Mérillon JM., Ramawat K., editors Bioactive Molecules in Food. Reference Series in Phytochemistry. Springer, Cham. 2018.
17. Tsao R. Chemistry and Biochemistry of Dietary Polyphenols. Nutrients. 2010; 2: 1231-1246.

18. Krishnaiah D, Sarbatly $R$, Nithyanandam R. A review of the antioxidant potential of medicinal plant species. Food and Bioproducts Processing. 2011; 89: 217-233

19. Biswas SK, McClure D, Jimenez LA, Megson IL, Rahman I. Curcumin induces glutathionebiosynthesis and inhibits NF-kappaB activation and interleukin-8 release in alveolar epithelialcells: mechanism of free radical scavenging activity. Antioxid Redox Signal. 2005; 7: 3241.

20. Guo KJ, Xu SF, Yin P. Active components of common traditional Chinese medicine decoctions have antioxidant functions. J Anim Sci. 2011; 89: $3107-$ 3115.

21. Borkar SD, Naik R, Shukla VJ, Acharya R. Evaluation of phytochemical content, nutritional value and antioxidant activity of Phanji - Rivea hypocrateriformis (Desr.) Choisy leaf Ayu. 2015; 36: 298-302.

22. Kasote DM, Katyare SS, Hegde MV, Bae H. Significance of Antioxidant Potential of Plants and its Relevance to Therapeutic Applications. International Journal of Biological Sciences. 2015; 11: 982-991.

23. Mandal S, Yadav S, Yadav S, Nema RK. "Antioxidants: a review," Journal of Chemical and Pharmaceutical Research. 2009; 1: 102-104.

24. Lü JM, Lin PH, Yao Q, Chen C. Chemical and molecular mechanisms of antioxidants: experimental approaches and model systems. Journal of cellular and molecular medicine. 2010; 14: 840-860.

25. Xu DP, Li Y, Meng X, Zhou T, Zhou Y, Zheng J, et al. Natural Antioxidants in Foods and Medicinal Plants: Extraction, Assessment and Resources. International journal of molecular sciences. 2017; 18: 96.

26. Elshama S, Abdalla ME. Mohamed AM. Role of Natural Antioxidants in Treatment of Toxicity. Journal of Toxicological Analysis. 2018; 1: 1-7.

27. Sen S, Chakraborty R, Sridhar C, Reddy YS, De B. Free radicals, antioxidants, diseases and phytomedicines: current status and future prospect. International Journal of Pharmaceutical Sciences Review and Research. 2010; 91-100.

28. Wojtunik-Kulesza KA, Oniszczuk A, Oniszczuk T, Waksmundzka-Hajnos M. The influence of common free radicals and antioxidants on development of Alzheimer's Disease. Biomedicine \& Pharmacotherapy. 2016; 78: 39-49.

29. Fang $Y Z$, Yang S, Wu G. Free radicals, antioxidants, and nutrition. Nutrition. 2002; 18: 872-879.

30. Knight JA. Review: Free radicals, antioxidants, and the immune system. Annals of clinical and laboratory science. 2000; 30: 145-158.

31. Thorat I, Jagtap D, Mohapatra D, Joshi D, Sutar R, Kapdi S. Antioxidants, their properties, uses in food products and their legal implications. Int J Food Stud. 2013; 2, 81-104.

32. Bendary E, Francis RR, Ali HMG, Sarwat MI, El Hady S. Antioxidant and structure-activity relationships (SARs) of some phenolic and anilines compounds,Annals of Agricultural Sciences. 2013; 58: 173-181.

33. Nimse SB, Pal D. Free radicals, natural antioxidants, and their reaction mechanisms. RSC Advances. 2015; 5: 2798628006

34. De La Cruz JP, Ruiz-Moreno MI, Guerrero A, López-Villodres JA, Reyes $\mathrm{JJ}$, Espartero JL, et al. Role of the catechol group in the antioxidant and neuroprotective effects of virgin olive oil components in rat brain. The Journal of Nutritional Biochemistry. 2015; 26: 549-555.

35. Franco R, Navarro G, Martínez-Pinilla E. Antioxidant Defense Mechanisms in Erythrocytes and in the Central Nervous System. Antioxidants (Basel, Switzerland). 2019; 8: 46.

36. Moon RJ, Martini A, Nairn J, Simonsen J, Young blood J. Cellulose nanomaterials review: structure, properties and nanocomposites. Chem Soc Rev. 2011; 40: 3941-3994.

37. Nemazifard M, Kavoosi G, Marzban Z, Ezedi N. Physical, mechanical, water binding, and antioxidant properties of cellulose dispersions and cellulose film incorporated with pomegranate seed extract, International Journal of Food 
Properties. 2017; 20: 1501-1514.

38. Heinze T. Cellulose: Structure and Properties. In: Rojas O. editors, Cellulose Chemistry and Properties: Fibers, Nanocelluloses and Advanced Materials. Advances in Polymer Science. 2015; 271.

39. Väisänen S, Pönni R, Hämäläinen A. Quantification of accessible hydroxy groups in cellulosic pulps by dynamic vapor sorption with deuterium exchange. Cellulose. 2018; 25: 6923-6934.

40. Richards H, Baker P, Iwuoha E. Metal Nanoparticle Modified Polysulfone Membranes for Use in Wastewater Treatment: A Critical Review, Journal of Surface Engineered Materials and Advanced Technology. 2012; 2: 183-193.

41. El Fawal GF, Omer AM, Tamer TM. Evaluation of antimicrobial and antioxidant activities for cellulose acetate films incorporated with Rosemary and Aloe Vera essential oils. J Food Sci Technol. 2019; 56: 1510-1518.

42. Velásquez E, Rojas A, Piña C, Galotto C, López de Dicastillo MJC Development of Bilayer Biodegradable Composites Containing Cellulose Nanocrystals with Antioxidant Properties. Polymers. 2019; 11: 1945.

43. Criado P, Fraschini C, Salmieri S, Becher D, Safrany A, Lacroix M. Evaluation of Antioxidant Cellulose Nanocrystals and Applications in Gellan Gum Films. Industrial Biotechnology. 2015; 11: 59-68.

44. Davoodbasha MA, Saravanakumar K, Abdulkader AM, Lee S, Kim J. Synthesis of Biocompatible Cellulose-Coated Nanoceria with $\mathrm{pH}$ Dependent Antioxidant Property. ACS Appl. Bio Mater. 2019; 2: 1792-1801.

45. Chen Y, Liu X, Sun X, Zhang J, Mi Y, Li Q, et al. Synthesis and Antioxidant Activity of Cationic 1,2,3-Triazole Functionalized Starch Derivatives. Polymers. 2020; 12: 112 .

46. Azmi NS, Bahsa RK, Othman SH, Mohammed M. Characterization of antioxidant tapioca starch/polyaniline composites film prepared using solution casting method. Food Research. 2019; 3: 317-324.

47. Lozano-Navarro JI, Diaz-Zavala NP, Velasco-Santos C, Melo-Banda JA Páramo-Garcia U, Paraguay-Delgado F, et al. Chitosan-Starch Films with Natural Extracts: Physical, Chemical, Morphological and Thermal Properties. Materials. 2018; 11: 120 .

48. Zaidel DNA, Rashid JM, Hamidon NH, Salleh LM, Kassim ASM. Extraction and characterization of pectin from dragon fruit (hylocereus polyrhizus) peels. Chemical Engineering Transactions. 2017; 56: 805-810.

49. Kangani M, Hazeri N, Maghsoodlou MT. Hetero polysaccharide as a green and natural catalyst for the synthesis of dihydro-2-oxopyrroles and 3,4,5-trisubstituted furan-2(5h)-ones. Journal of the Chilean Chemical Society. 2018; 63: 4168-4172.

50. Smirnov V, Golovchenko V, Vityazev F, Patova O, Selivanov Y, Selivanova O. The Antioxidant Properties of Pectin Fractions Isolated from Vegetables Using a Simulated Gastric Fluid. Journal of Chemistry. 2017; 5898594: 10pages.

51. Valdés A, Burgos N, Jiménez A, Garrigós M. Natural Pectin Polysaccharides as Edible Coatings. Coatings. 2015; 5: 865-886.

52. Maftoonazad N, Badii F. Use of Edible Films and Coatings to Extend the Shelf Life of Food Products. Recent Patents on Food, Nutrition \& Agriculture. 2009; 1: 162-170.

53. Eça KS, Machado MTC, Hubinger MD, Menegalli FC. Development of Active Films from Pectin and Fruit Extracts: Light Protection, Antioxidant Capacity, and Compounds Stability. Journal of Food Science. 2015; 80: C2389-C2396.

54. Ahuactzi V, Ramírez-Rivas O, Dávila-Cruz A, Sánchez-Minutti L, GarcíaIgnacio $\mathrm{HM}$, Pérez $\mathrm{H}$, et al. Antioxidant activity of edible films developed with pectin of tejocote. Conference.

55. Yang S, Cheng K, Lin Y, Liu Y, Hou W. Pectin Hydroxamic Acids Exhibit Antioxidant Activities in Vitro. Journal of Agricultural and Food Chemistry. 2004; 52: 4270-4273.

56. Ahmadi A, Moghadamtousi S, Abubakar S, Zandi K. Antiviral Potential of Algae Polysaccharides Isolated from Marine Sources: A Review. Bio Med Research International. 2015; 10 pages.

57. Sellimi S, Younes I, Ayed $\mathrm{H}$, Maalej $\mathrm{H}$, Montero $\mathrm{V}$, Rinaudo $\mathrm{M}$, et al
Structural, physicochemical and antioxidant properties of sodium alginate isolated from a Tunisian brown seaweed. International Journal of Biological Macromolecules. 2015; 72: 1358-1367.

58. Nooeaid P, Chuysinuan P, Techasakul S. Alginate/gelatine hydrogels: characterisation and application of antioxidant release. Green Materials. 2017; 5: 153-164.

59. Kokilam G, Vasuki S, Sajitha N. Biochemical composition, alginic acid yield and antioxidant activity of brown seaweeds from Mandapam region, Gulf of Mannar. Inproceedings Biochemical CA, 2013.

60. Hadiyanto Suzery M, Setyawan D, Majid D, Sutanto $H$. Encapsulation of phycocyanin-alginate for high stability and antioxidant activity. In IOP Conference Series: Earth and Environmental Science, (Vol. 55). Institute of Physics Publishing. 2017.

61. Fabra MJ, López-Rubio A, Sánchez G, Falcó I, Randazzo W. Antiviral and antioxidant properties of active alginate edible films containing phenolic extracts. Food Hydrocolloids. 2018; 81: 96-103.

62. Kang HK, Seo CH, Park Y. The Effects of Marine Carbohydrates and Glycosylated Compounds on Human Health. Int J Mol Sci. 2015; 16: 60186056

63. Mukhamejanov E, Kurilenko V. Fucoidan: A nutraceutical for metabolic and regulatory systems homeostasis maintenance. World Journal of Advanced Research and Reviews. 2020; 06: 255-264.

64. Wang $\mathrm{Y}$, Xing M, Cao Q, Ji A, Liang H, Song S. Biological Activities of Fucoidan and the Factors Mediating Its Therapeutic Effects: A Review of Recent Studies. Mar Drugs. 2019; 17: 183.

65. Kordjazi M, Etemadian Y, Shabanpour B, Pourashouri P. Chemical composition antioxidant and antimicrobial activities of fucoidan extracted from two species of brown seaweeds (Sargassum ilicifolium and $\mathrm{S}$. angustifolium) around Qeshm Island. Iranian Journal of Fisheries Sciences. 2019; 18: 457-475

66. Audrey Koh $\mathrm{H}, \mathrm{Lu}$ J, Zhou W. Structure characterization and antioxidan activity of fucoidan isolated from Undaria pinnatifida grown in New Zealand, Carbohydrate Polymers. 2019; 212: 178-185.

67. Neri TA, Rohmah Z, Ticar BF, Palmos GN, Cho B. Evaluation of sea mustard (Undaria pinnatifida) sporophylls from South Korea as fucoidan source and its corresponding antioxidant activities. Fisheries and Aquatic Sciences. 2019; 22: 1-7.

68. Al-Khatib BYH, Al-Hamdani NMH, Gumaih HSA. Ameliorated and antioxidant effects of Fucoidan against cyclosporine A-induced kidney injury in rats. The Journal of Basic and Applied Zoology. 2019; 80: 40.

69. Mampho C, Pandey S, Ramontja J, Fosso-Kankeu E, Waanders F Synthesis and Characterization of Superabsorbent Hydrogels Based on Natural Polymers: Kappa Carrageenan. Int'l Conf. on Advances in Science, Engineering, Technology \& Natural Resources (ICASETNR-16). 2016; 24 25

70. Sokolova EV, Barabanova AO, Bogdanovich RN, Khomenko VA, Solov'eva TF, Yermak IM. In vitro antioxidant properties of red algal polysaccharides, Biomedicine \& Preventive Nutrition. 2011; 1: 161-167.

71. Sun $\mathrm{T}$, Tao $\mathrm{H}, \mathrm{Xie} \mathrm{J}$, Zhang $\mathrm{S}, \mathrm{Xu} X$. Degradation and antioxidant activity of K-carrageenans. J Appl Polym Sci. 2010; 117: 194-199.

72. Shojaee-Aliabadi S, Hosseini H, Mohammadifar MA, Mohammadi A Ghasemlou M, Ojagh SM. Characterization of antioxidant-antimicrobial K-carrageenan films containing Satureja hortensis essential oil. International Journal of Biological Macromolecules. 2013; 52: 116-124.

73. Souza MP, Vaz AFM, Costa TB. Construction of a Biocompatible and Antioxidant Multilayer Coating by Layer-by-Layer Assembly of K-Carrageenan and Quercetin Nanoparticles. Food Bioprocess Technol. 2018; 11: 1050-1060.

74. Chen CY, Li H, Yuan YN, Dai HQ, Yang B. Antioxidant activity and components of a traditional Chinese medicine formula consisting of Crataegus pinnatifida and Salvia miltiorrhiza. BMC complementary and alternative medicine. 2013; 13: 99. 
75. Dou D, Leng $P$, Li $Y$, Zeng $Y$, Sun $Y$. Comparative study of antioxidant compounds and antiradical properties of the fruit extracts from three varieties of Crataegus pinnatifida. Journal of Food Science and Technology. 2013; 52: 430-436.

76. Zhu YZ, Huang SH, Tan BK, Sun J, Whiteman M, Zhu YC. Antioxidants in Chinese herbal medicines: a biochemical perspective. Nat Prod Rep. 2004 21: 478-489.

77. Ran X, Ma L, Peng C, Zhang H, Qin LP. Ligusticum chuanxiong Hort: A review of chemistry and pharmacology. Pharmaceutical Biology. 2011; 49: 1180-1189.

78. Yang Z, Xu Y, Jie G, He P, Tu Y. Study on the antioxidant activity of tea flowers (Camellia sinensis). Asia Pacific Journal of Clinical Nutrition. 2007; 16: 148-152. 5P.

79. Spadiene A, Savickiene N, Ivanauskas L, Jakstas V, Skesters A. Antioxidant effects of Camellia sinensis L. extract in patients with type 2 diabetes. Journal of Food and Drug Analysis. 2014; 22, 4: 505-511.

80. Chen IC, Chang HC, Yang HW, Chen G. Lin Evaluation of total antioxidan activity of several popular vegetables and Chinese herbs: a fast approach with $\mathrm{ABTS} / \mathrm{H} 2 \mathrm{O} 2 / \mathrm{HRP}$ system in microplates. Journal of Food and Drug Analysis. 2004; 12: 29-33.

81. Lee Y, Chuah AM, Yamaguchi T, Takamura H, Matoba T. Antioxidant Activity of Traditional Chinese Medicinal Herbs Food Science and Technology Research. 2008; 14: 205-210.

82. Yang $\mathrm{CH}$, Chang HW, Lin HY, Chuang LY. Evaluation of Antioxidant and Antimicrobial Activities from 28 Chinese Herbal Medicines. Journal of Pharmacognosy and Phytochemistry. 2013; 2: 294-305.

83. Temraz A, El-Tantawy WH. Characterization of antioxidant activity of extract from Artemisia vulgaris. Pakistan journal of pharmaceutical sciences. 2008; 21: 321-326.

84. Zhang S, Liu X, Zhang ZL, He L, Wang Z, Wang GS. Isolation and Identification of the Phenolic Compounds from the Roots of Sanguisorba officinalis L. and Their Antioxidant Activities. Molecules. 2012; 17: 1391713922.

85. Ding $\mathrm{H}$, Chou $\mathrm{T}$, Lin $\mathrm{R}$, Chan LP, Wang $\mathrm{GH}$, Liang $\mathrm{CH}$. Antioxidant and Antimelanogenic Behaviors of Paeonia suffruticosa. Plant Foods Hum Nutr. 2011; 66: 275-284.

86. He J, Dong Y, Liu X, Wan Y, Gu T, Zhou X, Liu M. Comparison of Chemical Compositions, Antioxidant, and Anti-Photoaging Activities of Paeonia suffruticosa Flowers at Different Flowering Stages. Antioxidants. 2019; 8 : 345.

87. Yang $\mathrm{CH}$, Li RX, Chuang LY. Antioxidant Activity of Various Parts of Cinnamomum cassia Extracted with Different Extraction Methods. Molecules. 2012; 17: 7294-7304.

88. Li M, Pare PW, Zhang J, Kang T, Zhang Z, Yang D, et al. Antioxidan Capacity Connection with Phenolic and Flavonoid Content in Chinese Medicinal Herbs. Rec Nat Prod. 2018; 12: 3, 239-250.

89. Sharma R. Molecular targets of common Ayurvedic herbal antioxidants Journal of Ayurvedic and Herbal Medicine. 2017; 3: 36-40.

90. Scartezzini P, Speroni E. Review on some plants of Indian traditional medicine with antioxidant activity,Journal of Ethnopharmacology. 2000; 71 1-2, 23-43.

91. Gangasagre JN, Gangasagre NS, Shaikh TA, Lahankar SM. Rasayana as antioxidant: an Ayurvedic perspective, International Journal of Medicine and Health Profession Research. 2017; 4: 31-34.
92. Naik GH, Priyadarsini KI, Satav JG, Banavalikar MM, Sohoni DP, Biyani MK, et al. Comparative antioxidant activity of individual herbal components used in Ayurvedic medicine, Phytochemistry. 2003; 63: 97-104.

93. Govindarajan R, Rastogi S, Vijayakumar M, Shirwaikar A, Rawat AKS, Mehrotra S, et al. Studies on the Antioxidant Activities of Desmodium gangeticum, Biological and Pharmaceutical Bulletin. 2003; 26: 10, 1424 1427

94. Zhou JX, Braun MS, Wetterauer P, Wetterauer B, Wink M. Antioxidant Cytotoxic, and Antimicrobial Activities of Glycyrrhiza glabra L., Paeonia lactiflora Pall., Eriobotrya japonica (Thunb.) Lindl. Extracts. Medicines 2019; 6: 43

95. Tohma HS, Gulçinl. Antioxidant and Radical Scavenging Activity of Aerial Parts and Roots of Turkish Liquorice (Glycyrrhiza Glabra L.), International Journal of Food Properties. 2010; 13: 4, 657-671.

96. Kant K, Walia M, Agnihotri VK, Pathania V, Singh B. Evaluation of Antioxidant Activity of Picrorhiza kurroa (Leaves) Extracts. Indian Journal of Pharmaceutical Sciences. 2013; 75: 324-329.

97. Sinha S, Bhat J, Joshi M, Sinkar V, Ghaskadbi S. Hepatoprotective activity of Picrorhiza kurroa Royle Ex. Benth extract against alcohol cytotoxicity in mouse liver slice culture. International Journal of Green Pharmacy. 2011; 5. 244-253.

98. Kiran B, Raveesha KA. In vitro Evaluation of Antioxidant Potentiality of Seeds of Psoralea corylifolia L. World Applied Sciences Journal. 2010; 8: 985-990.

99. Nabi NG, Shrivastava M. Phytochemical screening and Antioxidant Activity of Ethanol Extract of Psoralea corylifolia seeds.UK Journal of Pharmaceutical and Biosciences. 2017; 5: 01-07.

100. Poltanov EA, Shikov AN, Dorman HJD, Pozharitskaya ON, Makarov VG Tikhonov VP, et al. Chemical and antioxidant evaluation of Indian gooseberry (emblica officinalis gaertn., syn. phyllanthus emblica L.) supplements. Phytother Res. 2009; 23: 1309-1315.

101. Hasan R, Islam N, Islam R. Phytochemistry, pharmacological activities and traditional uses of Emblica officinalis: A review. International Current Pharmaceutical Journal. 2016; 5: 14-21.

102. Rocha Ribeiro SM, Queiroz JH. Lopes Ribeiro de Queiroz ME. Antioxidant in Mango (Mangifera indica L.) Pulp. Plant Foods Hum Nutr. 2007; 62: 13-17.

103. Martínez G, Delgado R, Pérez G, Garrido G, Núñez Sellés AJ, León OS. Evaluation of the in vitro antioxidant activity of Mangifera indica L. extract (Vimang). Phytother. Res. 2000; 14: 424-427.

104. Ramsewak RS, De Witt DL, Nair MG. Cytotoxicity, antioxidant and anti-inflammatory activities of Curcumins I-III from Curcuma Ionga, Phytomedicine. 2000; 7, 4: 303-308.

105. Suresh Kumara G, Nayakaa H, Dharmesha SM, Salimath PV. Free and bound phenolic antioxidants in amla (Emblica officinalis) and turmeric (Curcuma longa). Journal of Food Composition and Analysis. 2006; 19: 446452.

106. Semiz A, Sen A. Antioxidant and chemoprotective properties of Momordica charantia L. (bitter melon) fruit extract. African Journal of Biotechnology. 2007; 6: 273-277.

107. Sathishsekar D, Subramanian S. Antioxidant properties of Momordica Charantia (bittergourd) seeds on Streptozotocin induced diabetic rats. Asia Pac J Clin Nutr. 2005; 14: 153-158. 